Uluslararası Mühendislik

Cilt/Volume:12 Sayı/Issue:3 Aralık/December 2020 Özel Sayı/Special Issue

\title{
Fault Detection and Diagnosis Technic Using Electrical Characteristics of a PV Module and Machine Learning Classifier
}

\author{
Mouhamed Aghiad Raslan' ${ }^{1}$, Ertuğrul Çam ${ }^{1}$ \\ ${ }^{l}$ Faculty of Engineering, Department of Electrical \& Electronics Engineering, Kirkkale University, Kırlkkale, Turkey
}

Başvuru/Received: 25/10/2020

Kabul / Accepted: 08/12/2020

Çevrimiçi Basım / Published Online: 31/12/2020

Son Versiyon/Final Version: 31/12/2020

\begin{abstract}
The growth of photovoltaic power plants is continuously rising, this growth would not be possible without safety, monitoring, and fault detection systems. In this paper, the common faults of a typical photovoltaic power plant that may occur in a photovoltaic module are discussed. Also, the paper studies the electrical characteristics of a photovoltaic module operating under several faults' conditions applied on a specially designed module that measures the output current of each substring by utilizing sensitive Hall Effect sensors. After obtaining the electrical characteristics under faults, using machine learning, two decision trees classifier models are trained, the first classifier is trained to detect and recognize faults. However, this classifier may confuse the partial shading case with several other faults. Hence, the second decision tree classifier is trained to distinguish the exact fault type when the module is operating under partial shading condition by applying a short-circuit test on the photovoltaic module. This design can be achieved by connecting current sensors in the junction box of a typical photovoltaic module.
\end{abstract}

Keywords

"Photovoltaic systems, Fault detection, machine learning classifiers, Fault recognition." 


\section{Introduction}

Due to the continuous population increase and industrial growth, the energy demand increases proportionally. Today, more than $80 \%$ of the energy around the globe is produced from fossil fuel and nonrenewable energy resources, oil, coal, and natural gas being the top of the list (Key world energy statistics, 2019). Harvesting for energy sources with today's living standards opened the door to renewable energy power plants' growth. By the end of 2018, the total renewable energy capacity in the world, except hydropower, has reached 1179 GW (BP Energy, 2019). According to data gathered from the Republic of Turkey Energy Market Regulatory Authority's report (EPDK) (EPDK, 2018) and Turkey Electricity Transmission Company (TEİAŞ) (TEİAŞ, 2019), Turkey's total installed capacity and power generation have increased from 44,761 MW in 2009 to 91,267 MW in 2019, and from 194,813 GWh in 2009 to 303,655 GWh in 2019, respectively. In other words, Turkey's installed capacity and power generation have increased from 2009 to $2019,103 \%$ and $56 \%$ respectively.

Due to the geographical location of Turkey, it has a high potential for solar power, according to the Solar Energy Potential Atlas (SEPA), which was provided by the Ministry of Energy and Natural Resources, the estimated annual sunshine duration is 2,737 hours (7.5h daily), this leads to an annual solar power of $1,527 \mathrm{kWh} / \mathrm{m}^{2}$ (SEPA, 2018). As of the end of October 2020, the total solar energy power plants in Turkey has reached 7,104 power plant with a total capacity of 6,454 MW (TEİAŞ, 2019).

This growth in solar power plants would not be possible without monitoring, safety, and fault detection systems in Photovoltaic (PV) power plants. By realizing that among the most important reasons affecting the output power rate of a PV panel is, dirt-dust, partial shading condition, line-to-line fault, arc fault, open circuit fault, bypass diode failure (Mellit et al., 2018)(Triki-Lahianiet al., 2018)(Köntges et al., 2018) and similar factors that prevent to the panel from producing the rated output power. Along with these possible faults, determining the performance of the PV power system, identifying faults, and tracking energy efficiency are among the main objectives of a monitoring system. Today's monitoring systems are usually done at the PV array level and on the inverter and Maximum Power Point Tracking (MPPT) unit sides (Rezk et al., 2017). Since there are too many panels in a medium and large PV plant, it is important to identify and locate the fault accurately and quickly in the event of a failure (Guerrieroet al., 2013). In PV systems, fault detection methods can generally be categorized as thermal, visual, and electrical methods (Andò et al., 2015). The approaches of electrical-based fault detection methods are, in turn; Approaches that do not need meteorological data such as irradiance values and temperature data, approaches in which the current and voltage characteristics of the PV power system are analyzed, approaches where the maximum power point is followed and using machine learning technics (Chine et al., 2016). In recent years, the use of machine learning and artificial intelligence techniques in fault detection in PV systems has been increasing.

The most common PV system faults are line-to-line fault, ground fault, open-circuit fault, soiling, partial shading, and bypass diode fault (Alam et al., 2015). A ground fault in PV systems is in short, an accidental connection between one point in the PV array and the ground, this connection leads to a significant current passing from the PV array to the ground. Ground faults occur due to cable insulation damage, ground fault inside the PV modules, short-circuit in the connection box, etc. when a ground fault occurs and the PV arrays are not well-grounded, it might lead to an electric shock. while line-to-line fault occurs due to a low impedance path or a shortcircuit between two points in the PV arrays, in some cases, it may lead to a fire incident due to the reverse current flow (Duke Energy, 2011). The reasons for the line-to-line fault are basically the same as the ground fault's reasons. Basically, the line-to-line fault and the ground fault can be represented as short-circuit fault. Partial shading can be defined as non-uniform irradiance in the PV system, the main causes of this condition are heavy dust or leaves, bird dropping, and other natural factors. Partial shading causes hotspots that may accelerate the aging of PV modules, besides decreasing the power efficiency. Overcurrent and ground fault protection devices, as well as arc-fault circuit interrupters, are used in PV systems to reduce the risk of catastrophic disasters (Alam et al., 2015), (Zhao et al., 2014). However, these protection devices and technics may not be triggered by some of the moderate faults in PV systems, as these faults will reduce the power efficiency and the lifetime of PV arrays due to the nonlinear output characteristics of PV arrays and the current-limiting nature (Zhao et al., 2012). Therefore, PV arrays still need to be monitored continuously along with periodic maintenance to maintain the rated efficiency, lifetime, and safety. However, conventional checking methods and maintenance of a PV system tend to be time-consuming, subjective, have low accuracy, and potentially critical to the operators (Chouder \& Silvestre, 2010), (Hernandez \& Vidal, 2009). During the past decade, automatic fault detection and monitoring technics of PV systems have drawn the attention of researchers and engineers and become one of the major topics of research in the field of photovoltaic systems (Spagnuolo et al., 2015). In recent years, many kinds of monitoring and fault detection methods and diagnostic techniques of PV systems have been proposed, these approaches can be categorized into conventional threshold identifying methods, and machine learning and artificial intelligence approaches.

Several thresholding fault detection approaches have been proposed previously based on the analysis of output electrical characteristics (power, current, and voltage). For instance, Drews et al. (2007) proposed an approach based on satellite-derived irradiance inputs, these inputs are inserted into a simulation of a grid-connected PV system (Drews et al., 2007). The yields from the simulation then are matched with the measured yields from the actual system. The differences between the measured outputs and the simulation's outputs are analyzed for failure detection. Gokmen et. al. (2013) proposed a method for short-circuit and open-circuit fault detection and also differentiate them from the partial shading condition, by calculating the ambient temperature and the operating voltage of the PV string (Gokmenet al., 2013). This method assumes that the PV array is operating under maximum power point (MPP). However, the operating 
point is not the actual MPP, due to the continuously varying irradiance and temperature, as well as the limited ability of the maximum power point tracking (MPPT) unit of keeping the array operating under MPP. In addition, the PV arrays' operating point only provides a small amount of data, which could be insufficient for locating and detecting a failure, and that might extremely alter the fault detection performance. Ali et. al. (2017) developed a real-time fault diagnosis and monitoring method by obtaining the voltage and current readings from the faulty PV panel and compare them with its accurate model, by identifying some specific characteristics and deformations on the I-V curve that differentiate each fault on the PV panel. This technic recognizes interconnection resistance faults and some different shading conditions (Ali et al., 2017). However, this method is still based on identifying a threshold for normal operation and PV panel operating under fault. The measurements were done under ideal conditions to define the normal operation and under fault conditions, as mentioned in the literature the PV panel operates under different uncontrollable conditions such as solar irradiance and ambient temperature. Mekki et. at. (2016) introduced a fault diagnosis method for partially shaded PV modules. This technic uses an artificial neural network to estimate the output power of a PV module under different conditions. The method relies on measuring the output current and voltage and measuring the cell's temperature. By analyzing the estimated output power with the measured data yields together achieves useful information on the operating status of the PV module (Mekki et al., 2016). However, the observed data cannot differentiate the fault type and the location of the fault in the PV system.

In this paper, based on the voltage and current output characteristic of the PV module, a decision tree classifier is trained to analyze the output of each substring current in the PV module and the overall output voltage to differentiate the type of fault in real-time. The trained model is able to identify automatically several different common faults in a PV system, including degradation fault, open-circuit fault, short-circuit fault, object or dirt on the PV panel, and different kinds of partial shading including soiling recognition. By connecting a Hall Effect sensor to each substring to measure the output current under several tests to identify and locate the fault in real-time. The proposed method operates under the PV module's MPP, and when analyzing more complicated faults such as degradation and soiling, the trained model inters to diagnosis mode, where it operates the PV module under short-circuit tests for fractions of a second to estimate the location and the type of the fault on substring levels. In this paper, a practical simulation of each fault is presented and carried out on a custom-made PV module for deep studying the electrical characteristics of a PV module operating under several different faults.

\section{Practical fault simulation}

To illustrate the impact of the faults on the output current and voltage of the studied PV module, these fault simulations are carried out by observing the changes of the four outputs, SS1, SS2, SS3, and Voltage, as shown in the module's scheme in Figure 1. The PV module is operating under $500 \mathrm{~W} / \mathrm{m}^{2}$ irradiance at $25^{\circ} \mathrm{C}$ temperature.

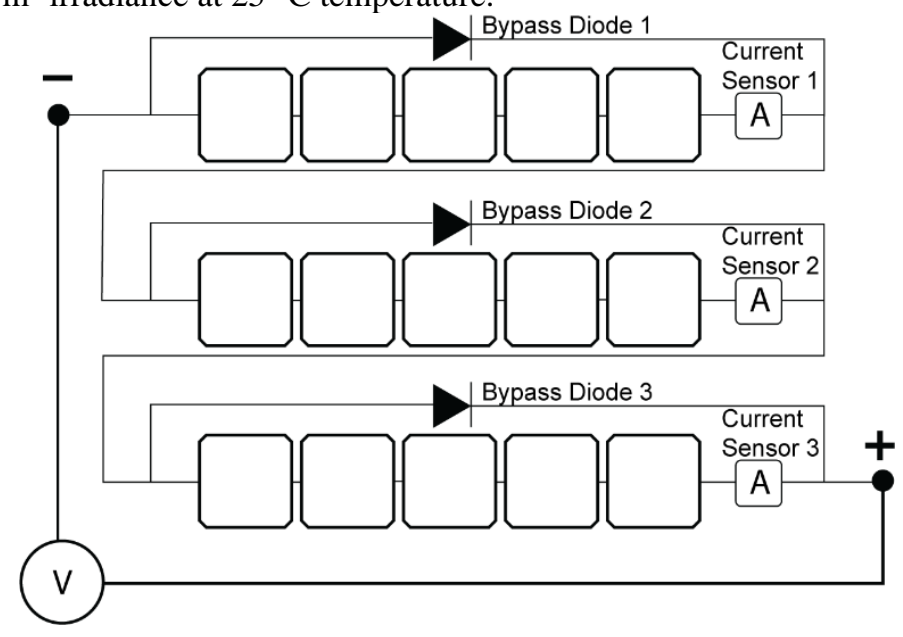

Figure 1. The electrical scheme of the PV module.

\subsection{Dirt test simulation}

This experiment is carried out by placing an object above one PV cell only. Shading one cell in a substring leads to a reverse bias on the behavior of the shaded cell (Jung et al., 2013). Figure 2 shows the effect of the shaded cell on the overall current of the substring that contains the shaded cell. also, a voltage drop is noticed due to the series connection of the substrings. 


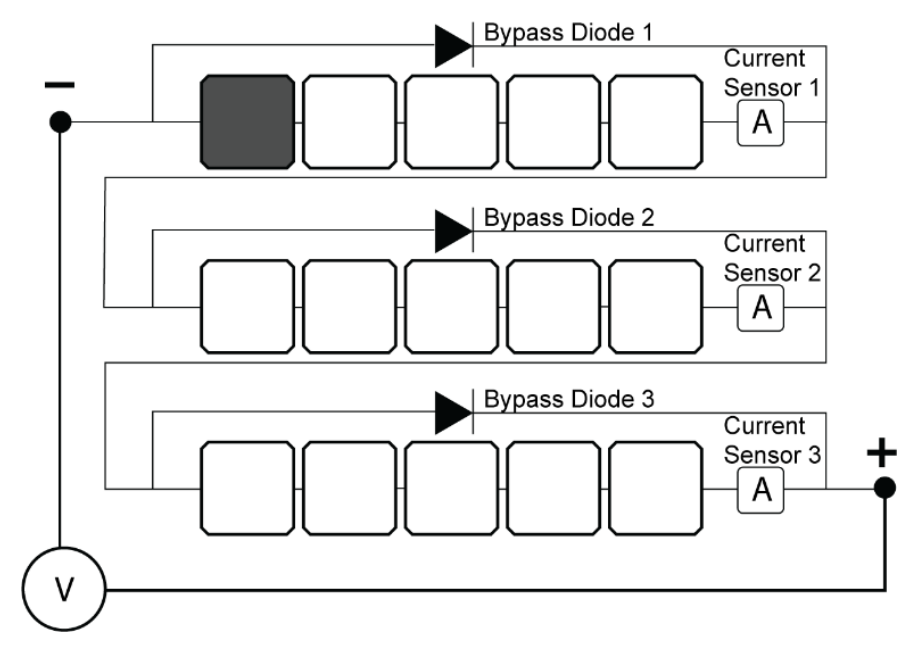

Figure 2. The dirt simulation applied to the PV module.

\subsection{Shading test 1 simulation}

In this experiment, an object is placed in front of the PV module shading partially several PV cells while operating under MPP load. Figure 3 shows the scheme of the PV panel along with the shaded PV cells.

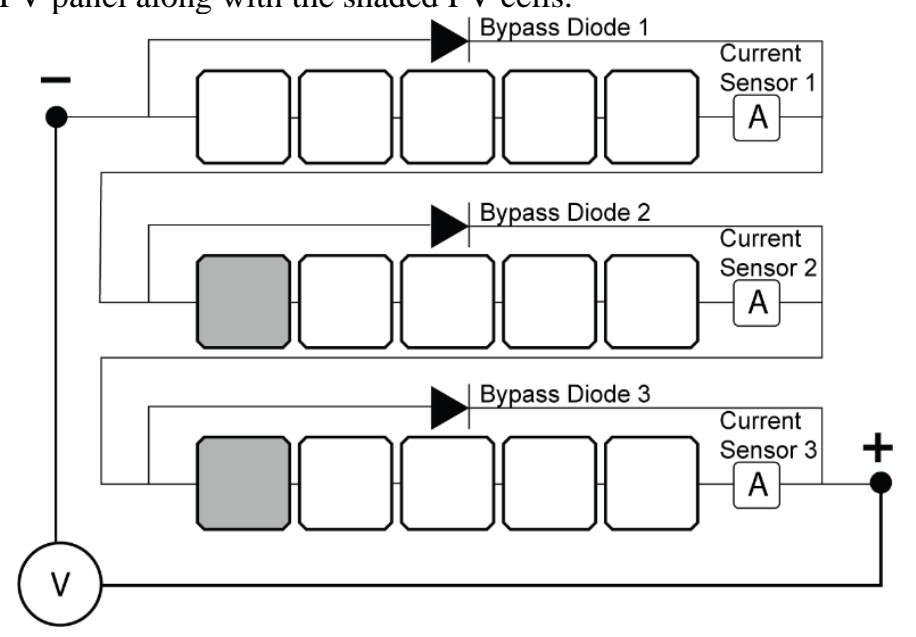

Figure 3. Partially shading the PV module under MPP load.

\subsection{Shading test 2 simulation}

This test illustrates the impacts of soiling of a PV module, where a tinted transparent sheet is placed above the PV module to represent a dusty PV panel, as shown in Figure 4, the scheme of the PV module completely shaded by a transparent sheet.

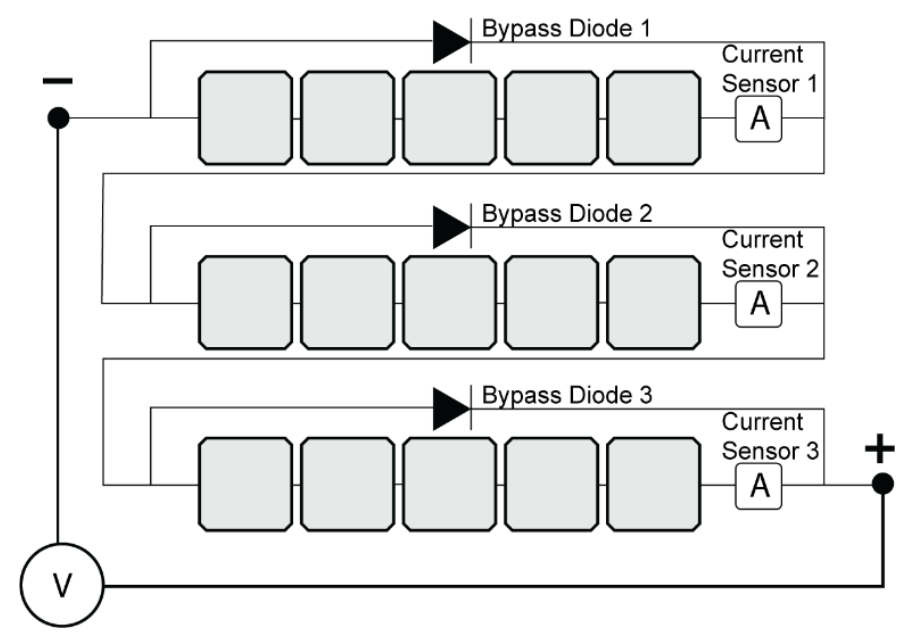

Figure 4. Scheme of the PV module shaded by a transparent sheet to simulate soiling condition. 


\subsection{Degradation test simulation}

Degradation fault in this simulation represents the interconnection failure in the ribbons of the PV cell, increase of the series resistance of a PV cell (Chen et al., 2017), and delamination of the front encapsulant (Triki-Lahianiet al., 2018). In this test, the degradation fault is achieved by adding a resistor in series to one of the substrings, this increases the series resistance Rs of the PV cells since it is more common and has a greater impact on the PV's power efficiency. The simulation is carried out by adding a 4-ohm resistor in series to substring 1 as shown in Figure 5.

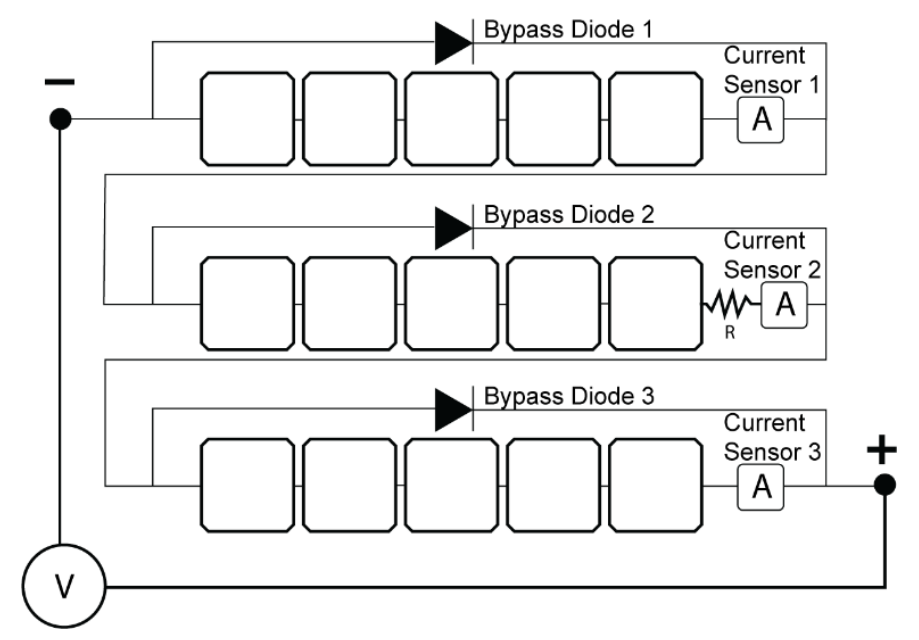

Figure 5. Degradation simulation test by connecting the resistor $\mathrm{R}=4 \mathrm{ohm}$.

\subsection{Bypass diode failure test simulation}

This experiment is simulated by short-circuiting the terminals of the bypass diode which is connected in parallel with a substring. In this case, the short-circuited substring's current is increased, and the output power is decreased significantly as the substring is considered completely canceled. Figure 6 illustrates the scheme of the PV module under the bypass diode fault.

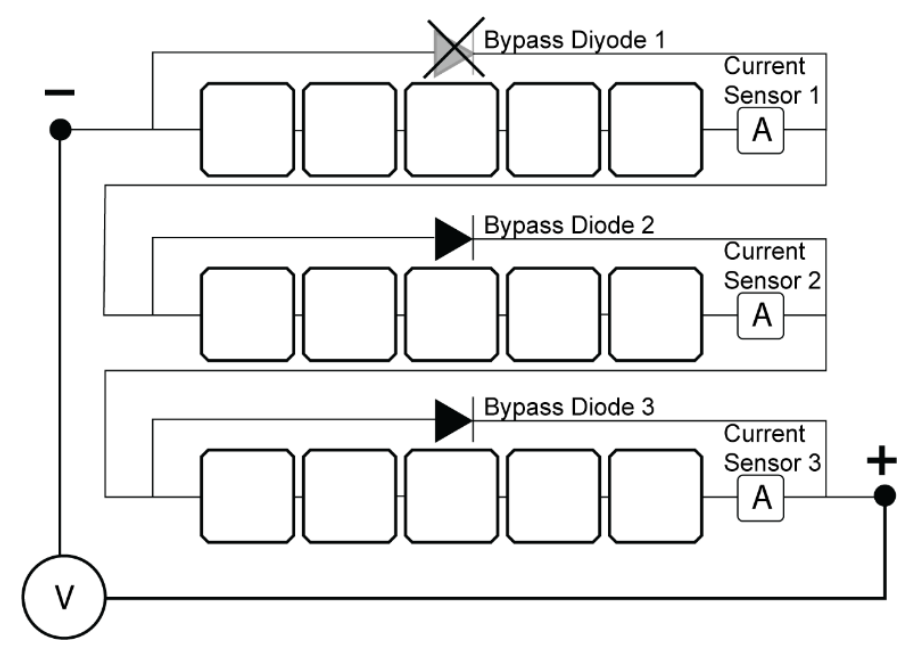

Figure 6. Bypass diode failure simulation test, Bypass Diode 1 is neglected.

\subsection{Short-circuit fault test}

It can be simply simulated by short-circuiting the terminals of the PV module as presented in Figure 7. 


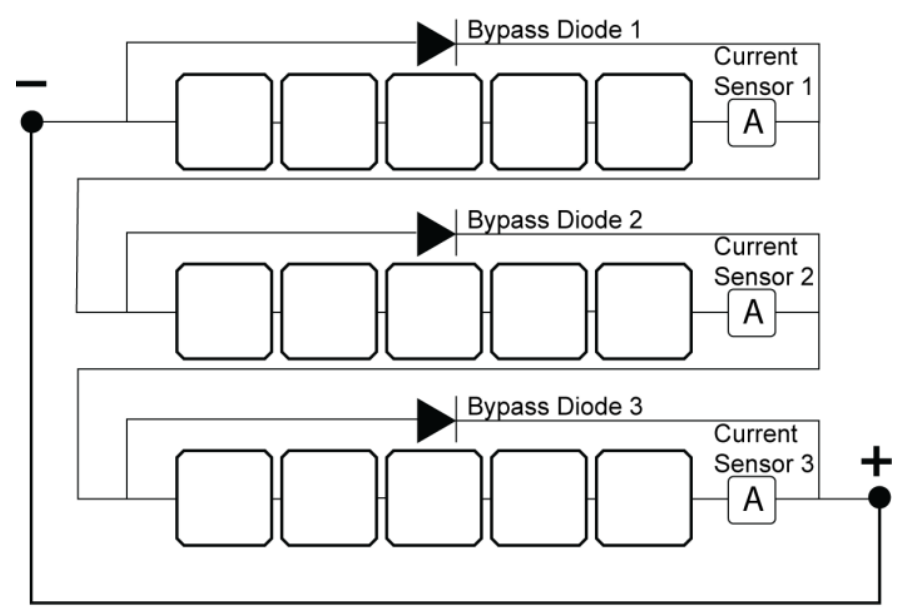

Short-Circuit

Figure 7. Short-circuit simulation on the PV module.

\subsection{Open-circuit fault test}

It can be achieved by simply disconnecting the load from the PV module.

\section{Decision tree model training}

This model is trained using 4 electrical parameters from the $\mathrm{PV}$ module including $\mathrm{SS}_{1}, \mathrm{SS}_{2}, \mathrm{SS}_{3}$, and $\mathrm{V}_{\text {out }}$, $\mathrm{SS}$ refers to the output current from a substring along with the number of the substring.

A decision tree classifier has been trained on over 3,500 sets of input data, the decision tree classifier has a solid advantage of using different decision rules along with feature subsets at a different level of classification (Du \& Sun, 2008). The training process was achieved through 4 major steps:

Step 1: acquiring parameters from the PV module under different types of faults and conditions, the acquired parameters are $\mathrm{SS}_{1}, \mathrm{SS}_{2}$, $\mathrm{SS}_{3}$, and $\mathrm{V}_{\text {out. }}$.

Step 2: classifying data according to each fault type, and certainly classifying the Normal condition when the PV module is operating under no-fault.

Step 3: dividing the data samples randomly into two data sets, training data sample, and testing data sample. The decision tree classifier is trained through the training data set, while the testing data set is utilized to validate the trained model.

Step 4: obtaining the trained decision tree model and insert it into the real-time data acquisition program for further testing.

The trained model's classes are divided into two branches, the first branch contains the detectable faults under MPP, while the second branch consists of fault detection using a short-circuit test. Figure 8 represents the flowchart of the fault detection process using two training data sets, one for MPP condition and one for short-circuit test. 


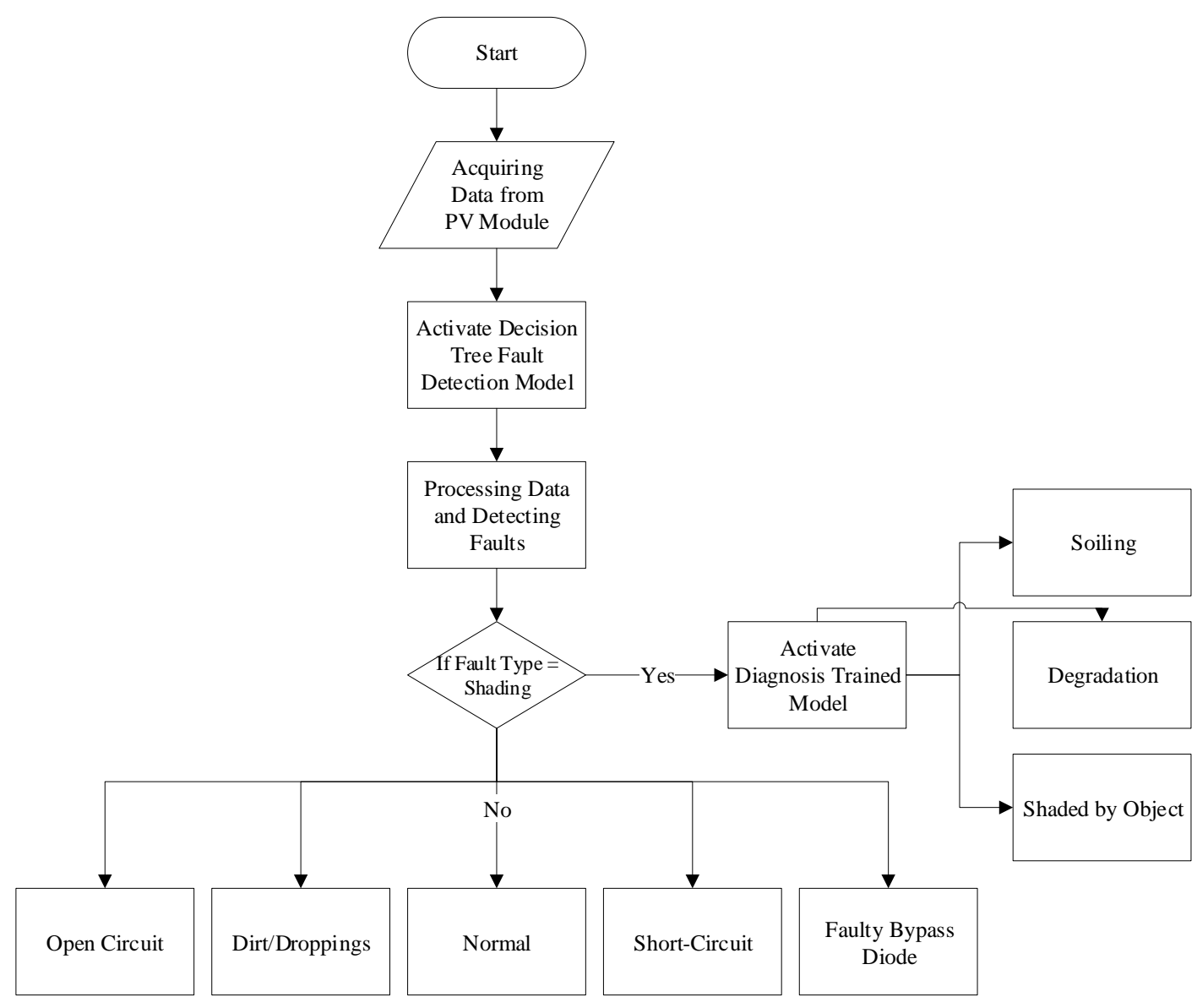

Figure 8. The work flow of the fault detection process.

The reason behind utilizing the short-circuit test is to identify the degradation fault and the soiling fault and to distinguish these two faults from the partial shading fault in case the PV module is shaded by an object. As is degradation or soiling cases, the first model will acquire a partial shading fault continuously, and in this case, the second model will be deployed to identify the fault and initiate the short-circuit test on the PV module. In literature, the degradation fault cannot be detected using the conventional measurement technics of the voltage and current of a PV module under the short-circuit test (Chen et al., 2017). However, the novelty of the proposed fault detection and recognition method is abbreviated by using measurements in substring levels that can distinguish the current differences from each substring under the short-circuit test. Figure 9 and Figure 10 shows the trained decision trees of normal operating condition and operating under the short-circuit condition. 


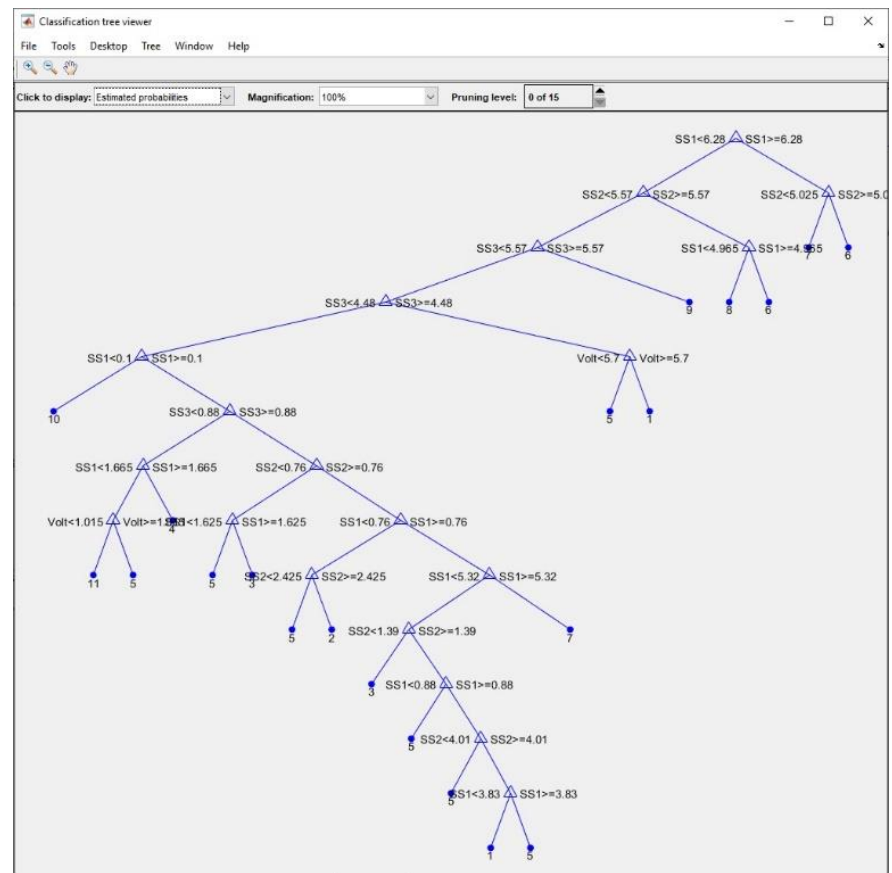

Figure 9. Fault detection decision tree of the trained model.

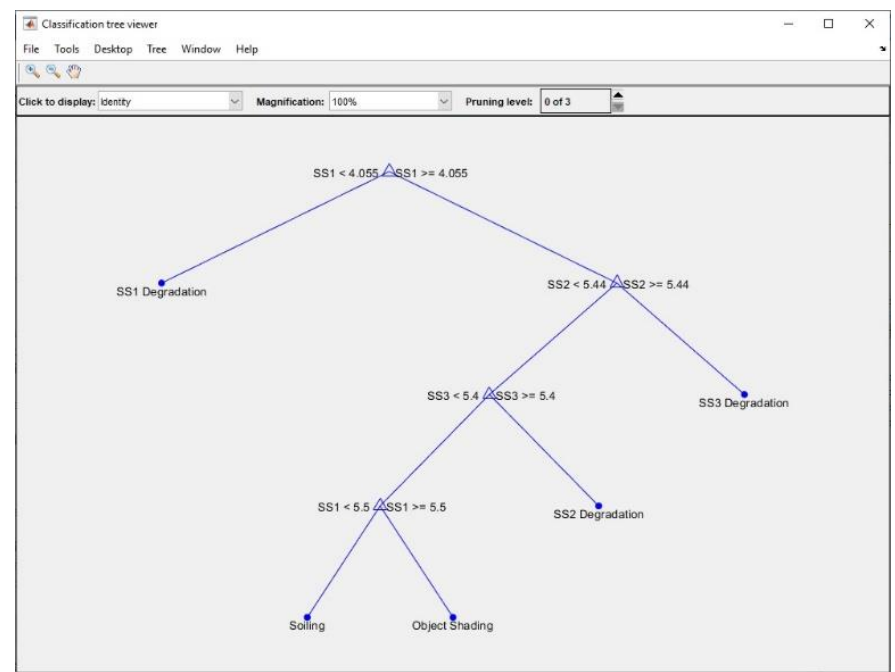

Figure 10. The decision tree of the diagnosis trained model for partial shading condition.

\section{Results}

After training the model using MATLAB Classifier Learner Application and optimizing the fault recognition, a confusion matrix is generated for each trained model. As shown in Figure 11. 


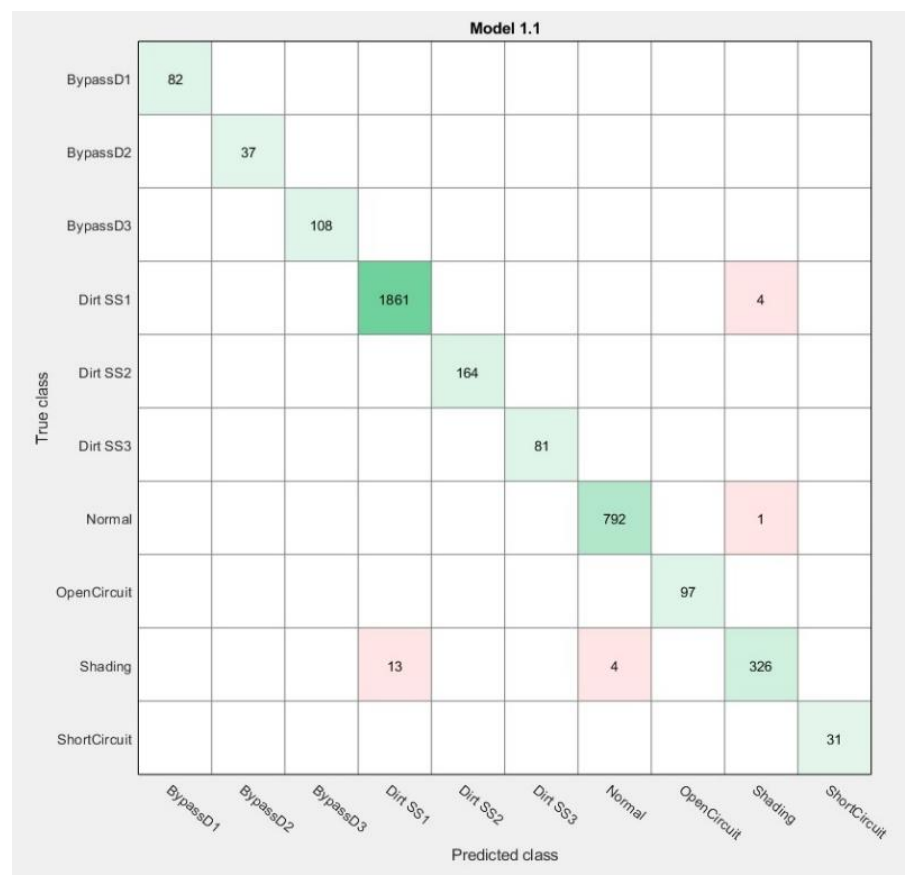

Figure 11. Confusion matrix of the fault detection trained model.

As for the second trained model that analyzes the continuous shading condition to distinguish the degradation and soiling faults, the confusion matrix is shown along with faults' classes in Figure 12.

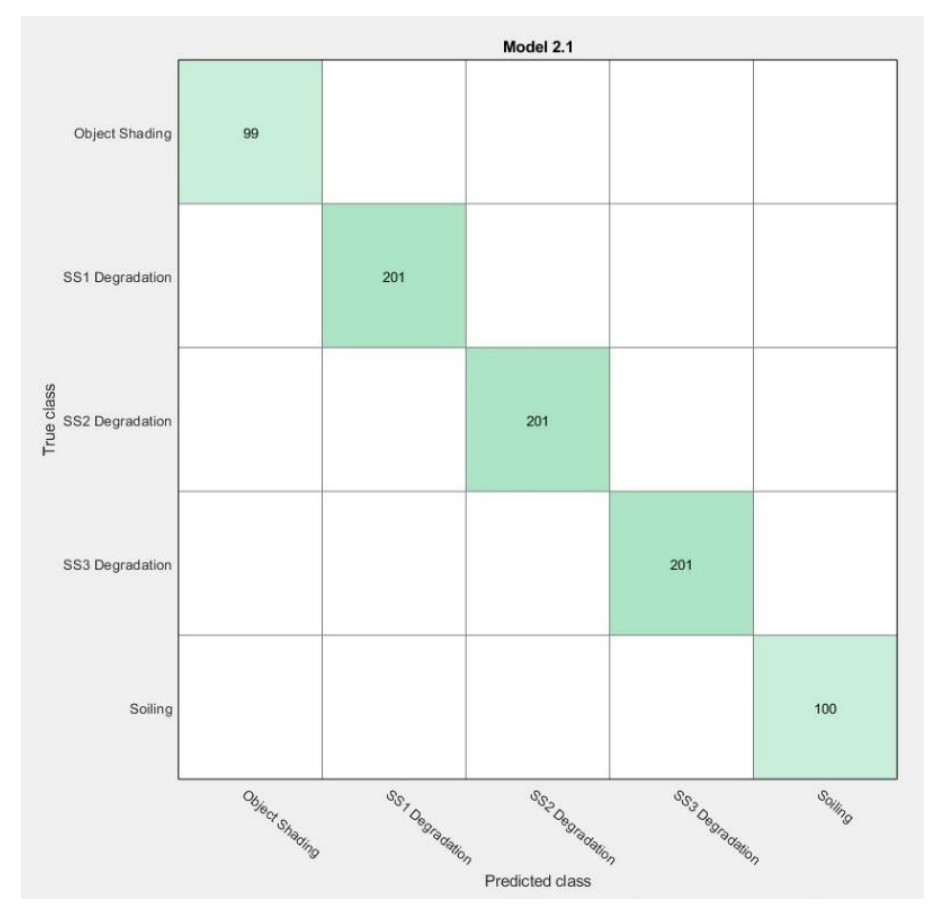

Figure 12. The confusion matrix of the trained diagnosis model.

In Figures 13 to 20, the data charts collected from the PV modules along with fault recognition results are shown. The results are obtained during real-time data acquisition and real-time fault detection. 


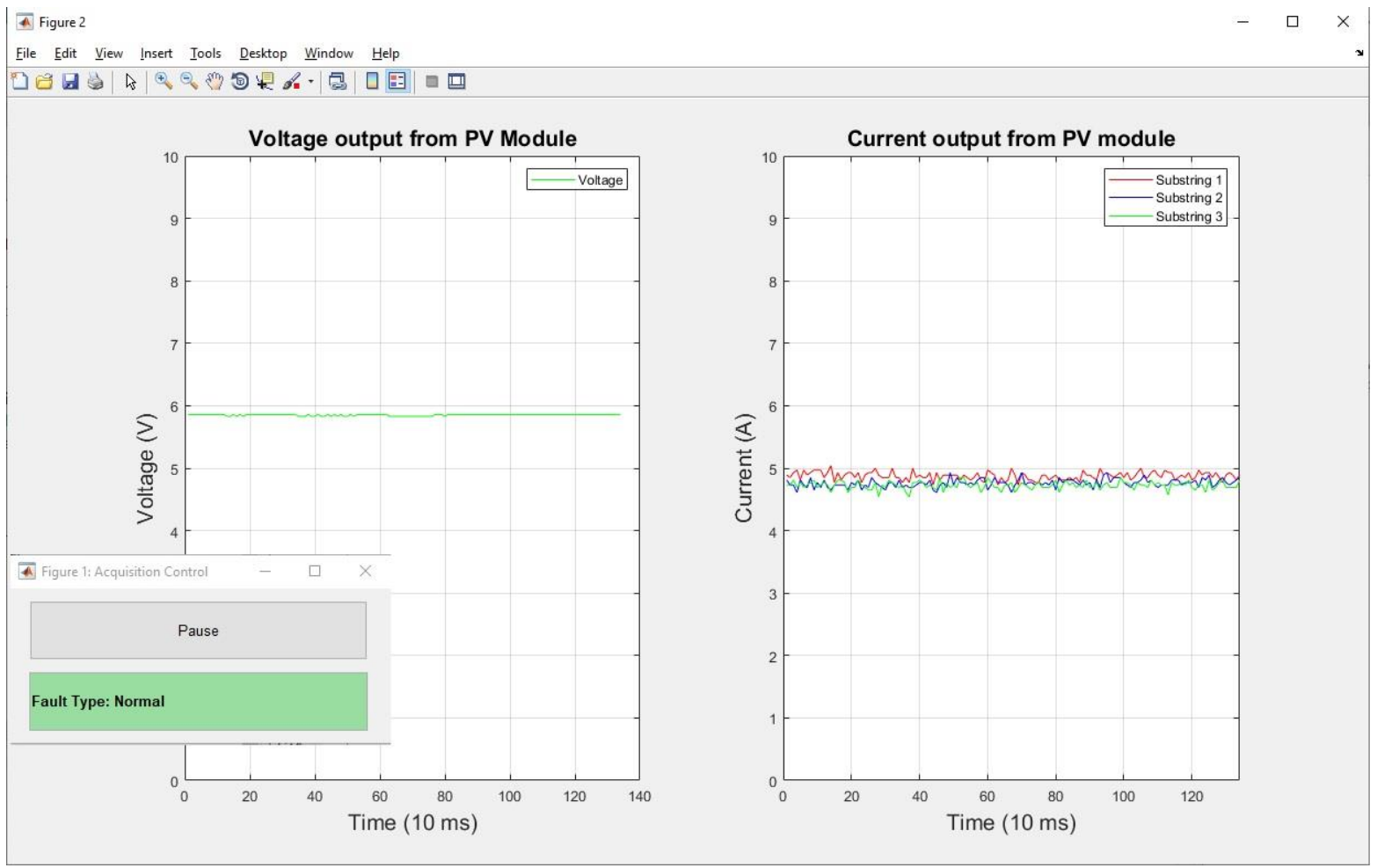

Figure 13. The PV module is operating normally under no fault condition; the prediction is shown in the colored box as: Normal.

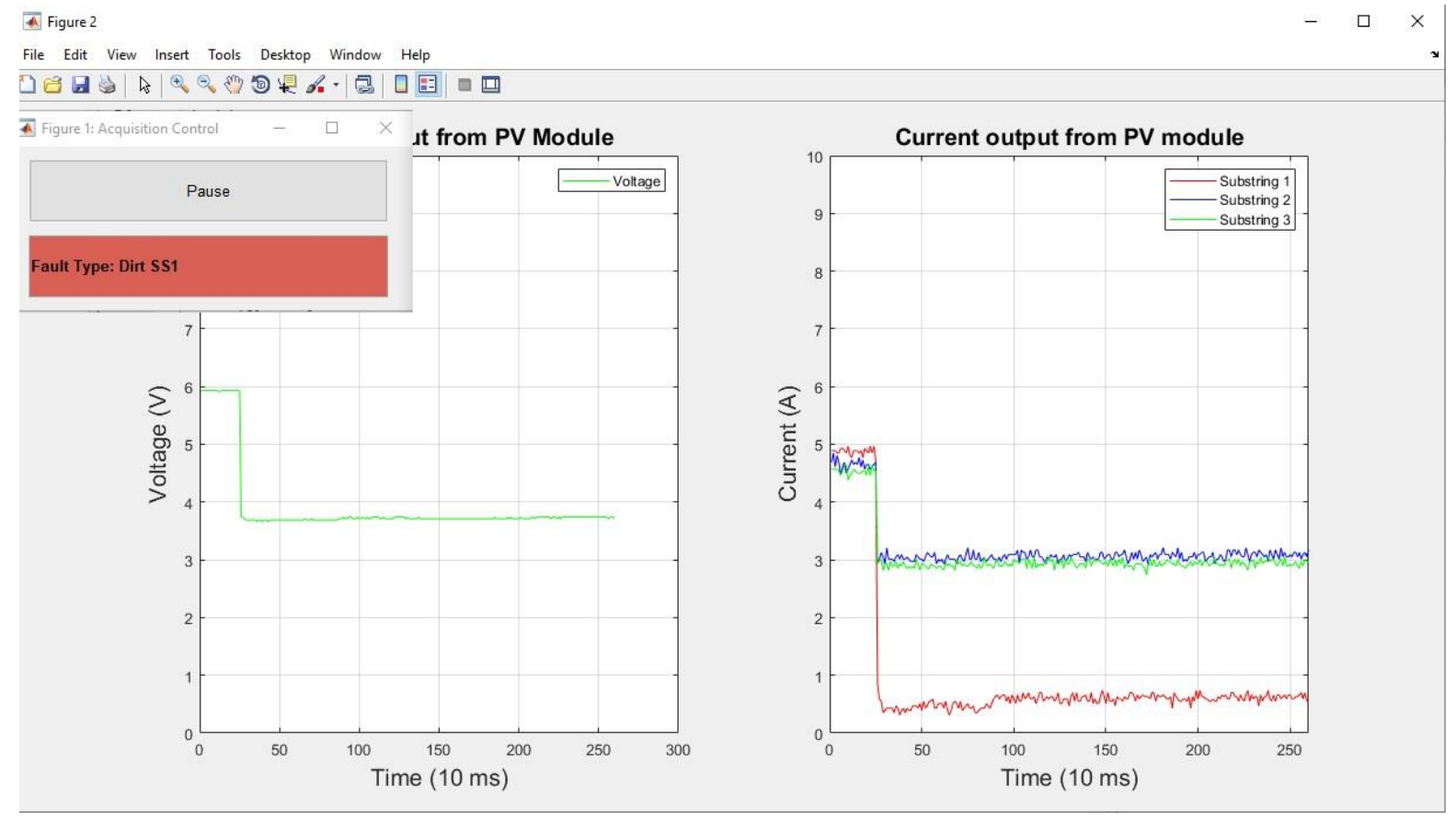

Figure 14. The PV module is operating under dirt condition by covering one PV cell from substring 1. 


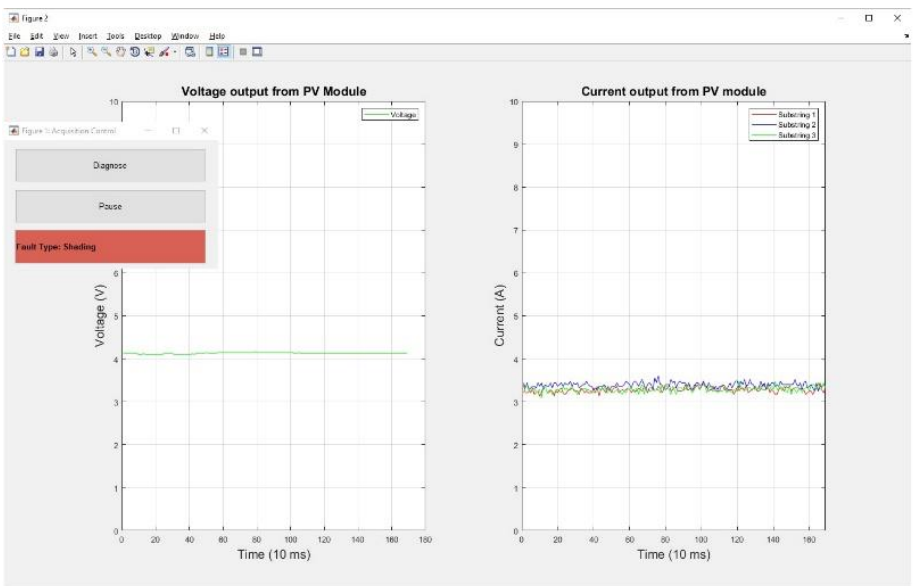

(a)

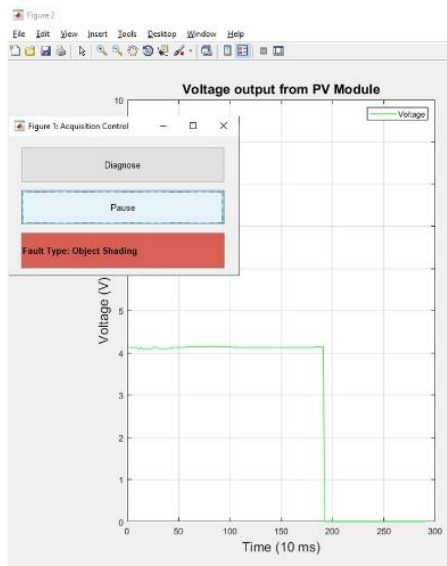

(b)

Figure 15. Shading test 1 results, (a) before activating the diagnosis model. (b) After activating the diagnosis model while the PV module is operating under short-circuit test.

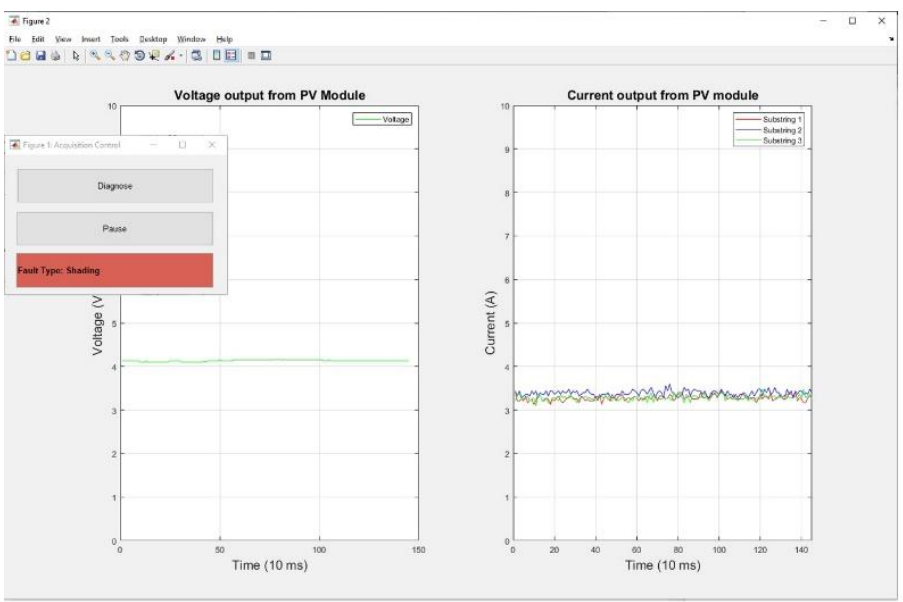

(a)

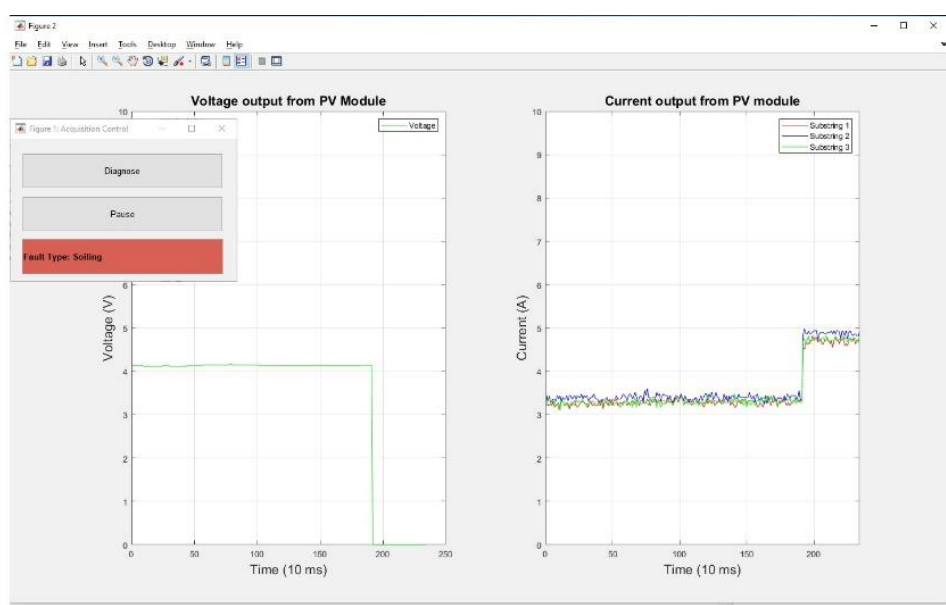

(b)

Figure 16. Shading test 2, (a) the fault detection model detecting shading. (b) fault diagnosis model recognizing soiling condition.

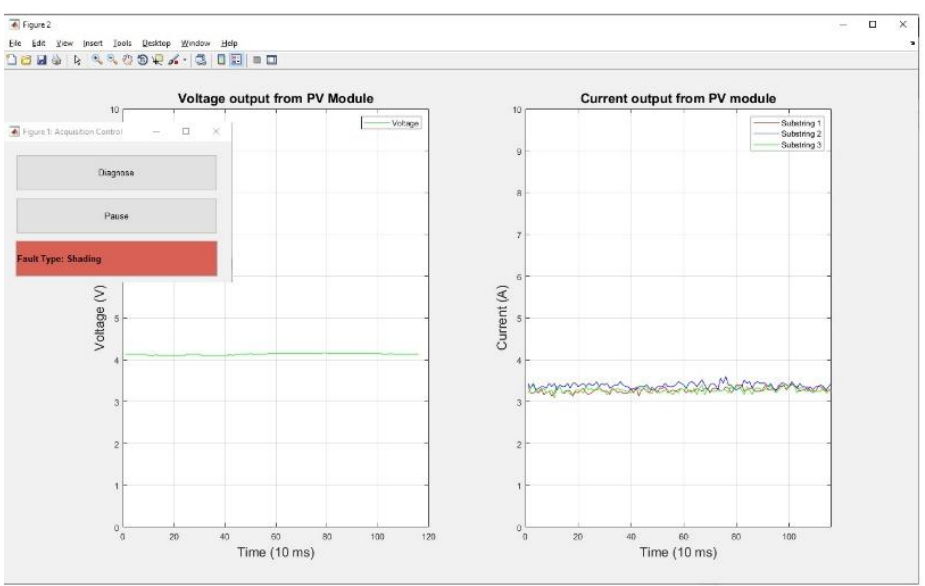

(a)

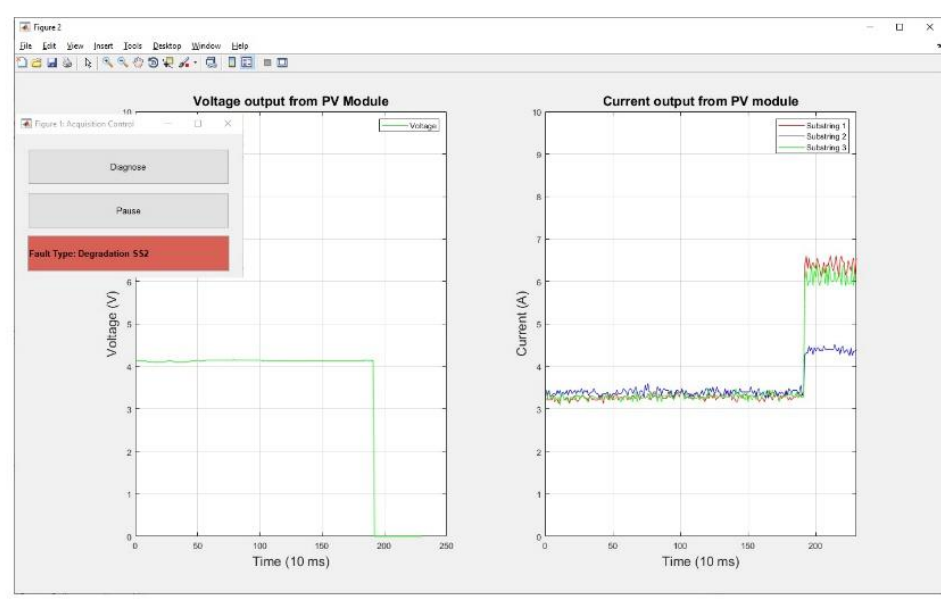

(b)

Figure 17. Degradation test results. (a) Degradation misread as shading by fault detection model. (b) Degradation recognized by the diagnosis model. 


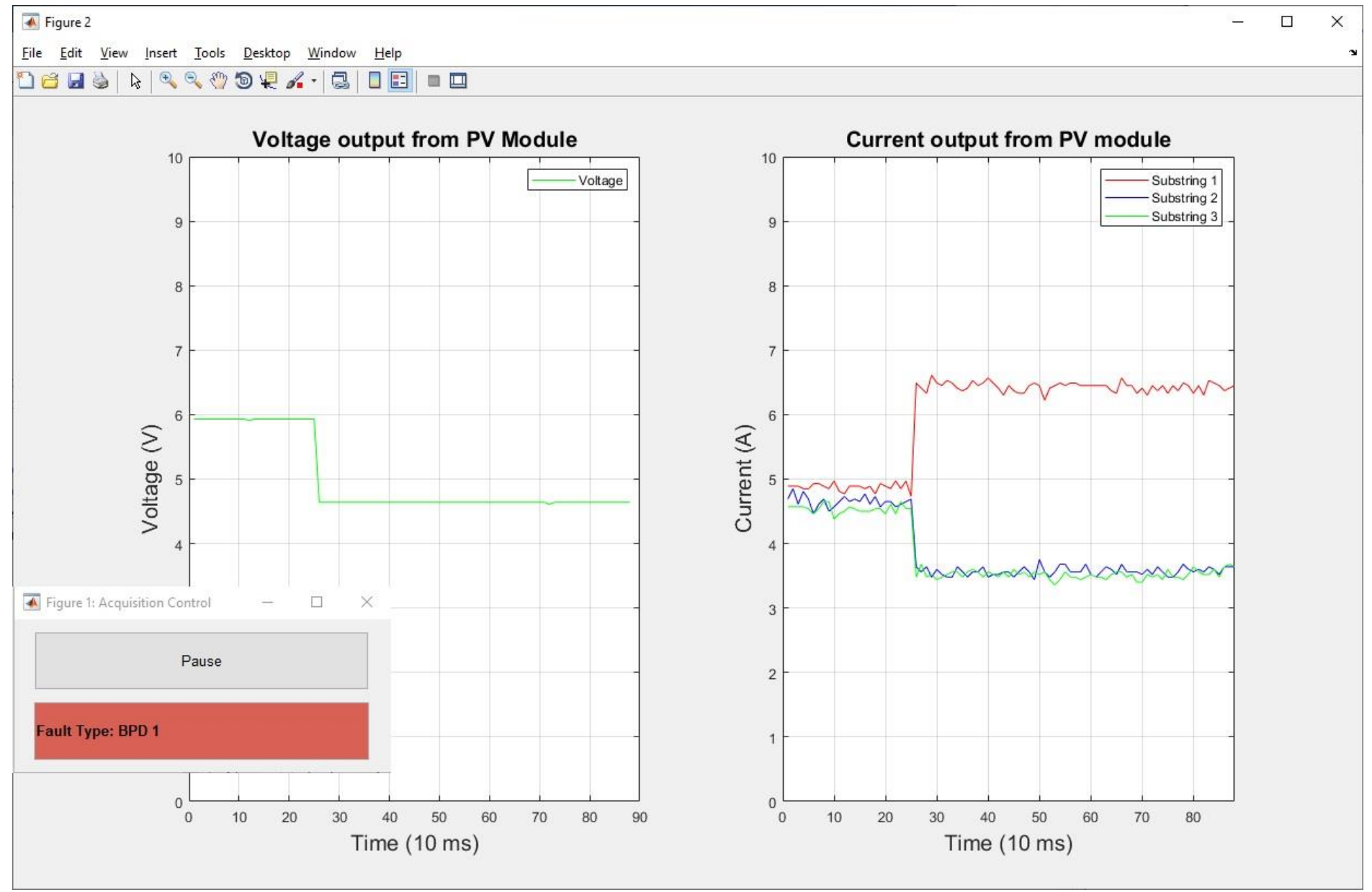

Figure 18. Bypass diode failure test recognized by fault detection model. 


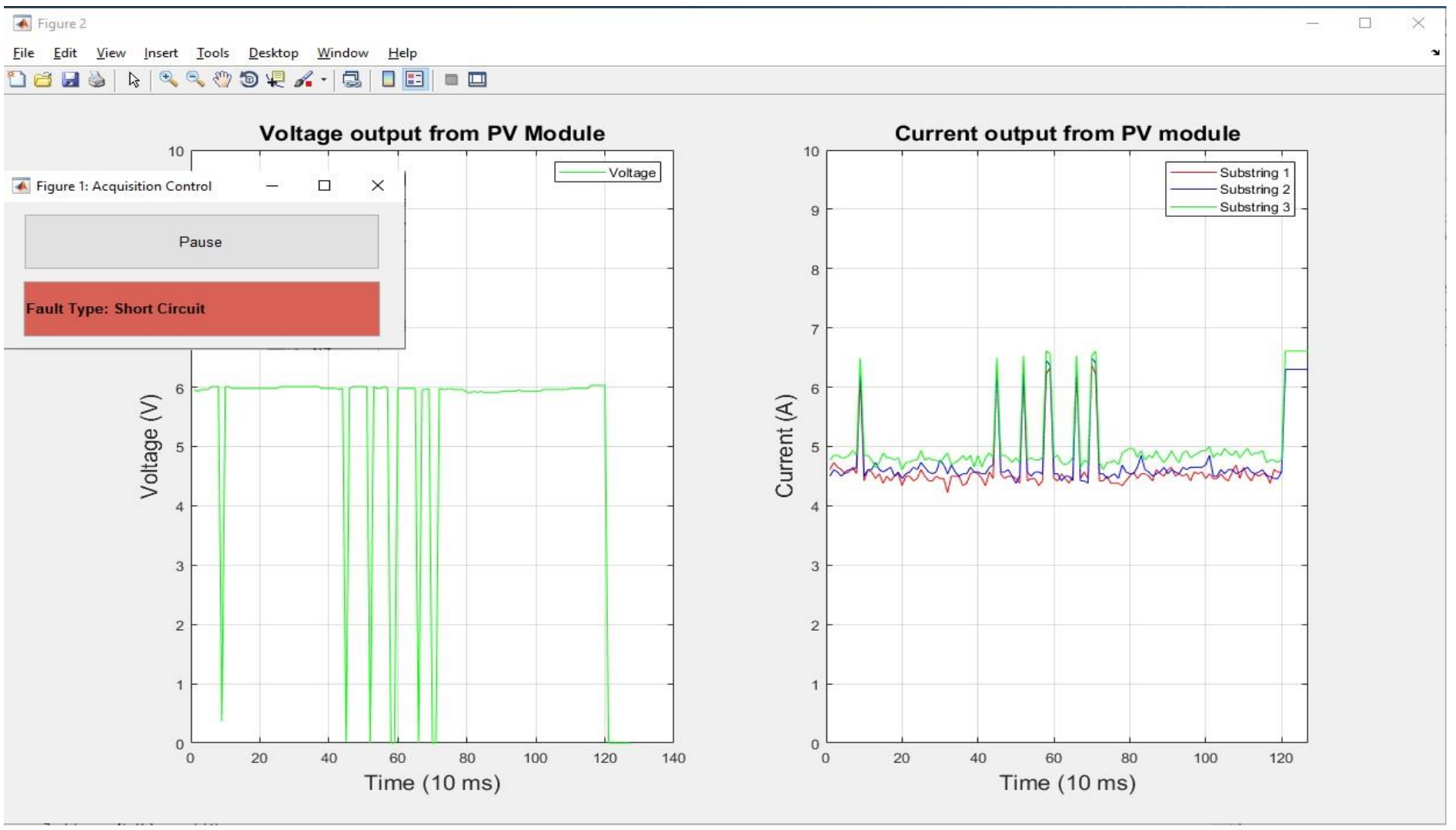

Figure 19. Short-circuit test detected by fault detection model. 


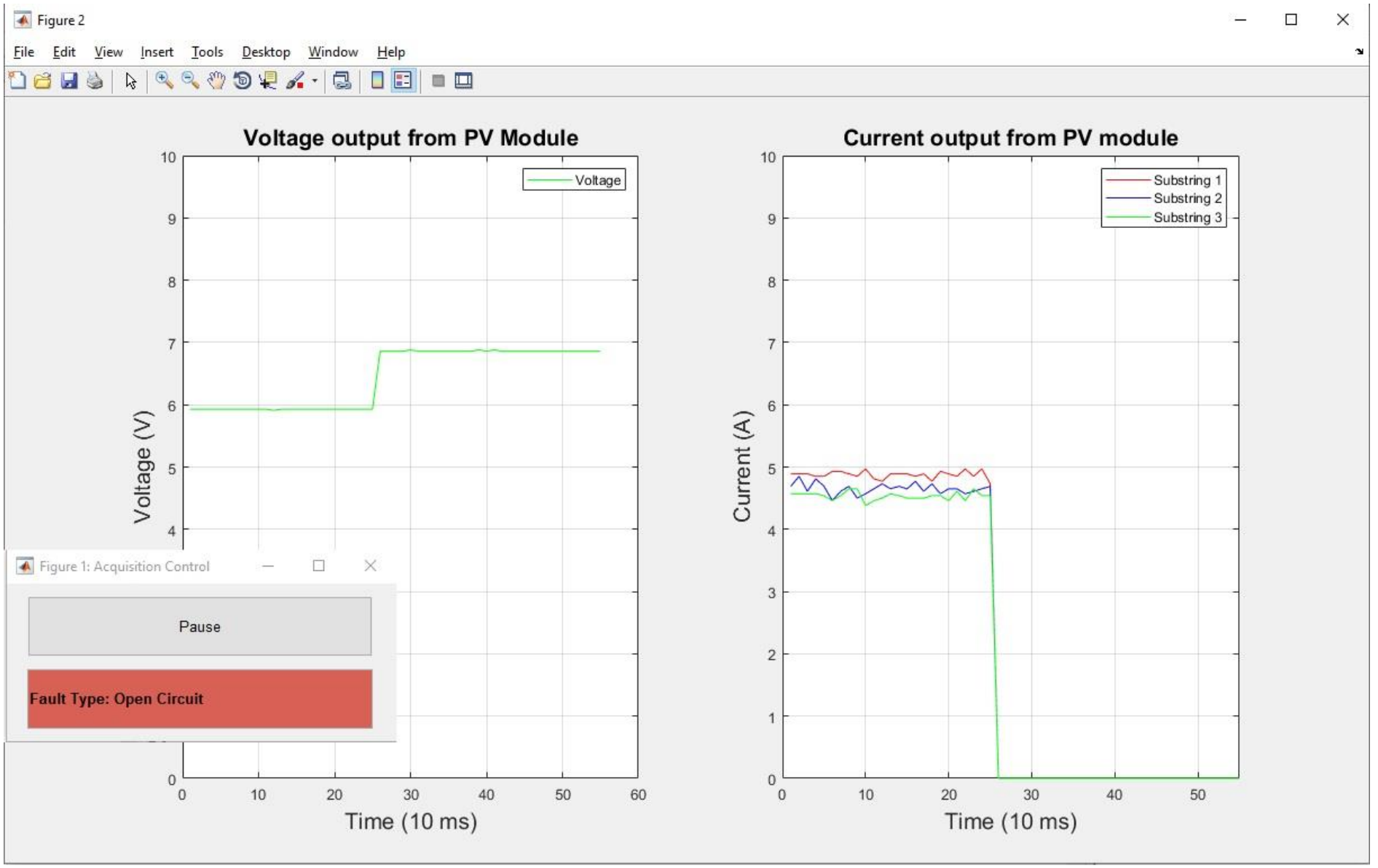

Figure 20. Open circuit fault detected by fault detection model.

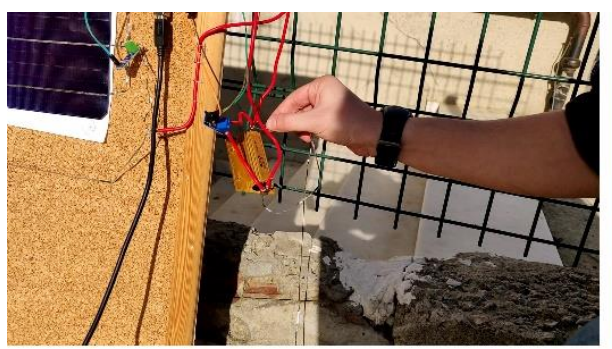

(a)

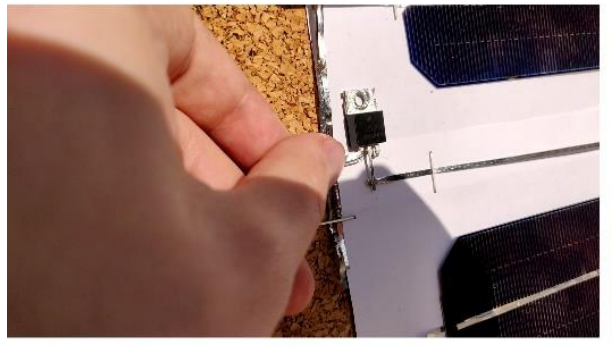

(c)

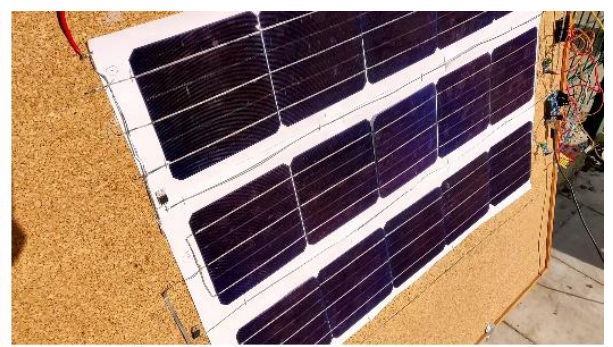

(b)

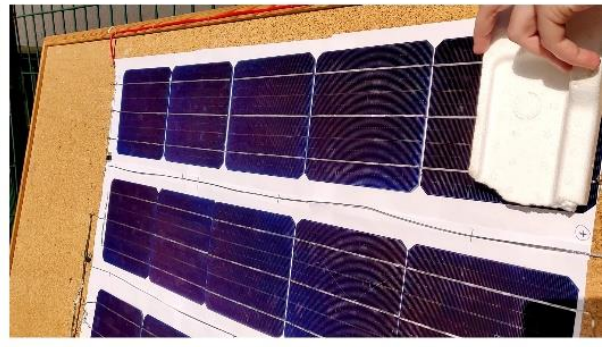

(d)

Figure 21. The PV module while applying the test, (a) Short-circuit test, (b) Normal operation, (c) Bypass diode failure, (d) Dirt shading test.

\section{Conclusion}

In this paper, based on the electrical characteristics of a PV module operating under fault and Decision tree classifier, a novel fault detection and recognition approach is proposed to accurately detect and identify some of the most common faults in a typical PV 
module. including short-circuit fault, open-circuit fault, bypass diode failure, degradation fault, and specifying the partial shading cases whether it is soiling, shaded by dirt, or shaded by an object. The fault detection and recognition Decision tree classifier is validated based on data sets acquired from an actual PV module operating under different conditions. The proposed model of the PV module can be achieved by connecting current measuring devices to the bypass diodes in the junction box of a typical PV module. It has proven its reliability in detecting and diagnosing the most common faults. This model can be improved by adding irradiance and temperature sensors to the module to increase the efficiency and reliability of the trained model.

\section{References}

Ali, M. H., Rabhi, A., El Hajjaji, A., \& Tina, G. M. (2017). Real time fault detection in photovoltaic systems. Energy Procedia, 111, 914-923.

Alam, M. K., Khan, F., Johnson, J., \& Flicker, J. (2015). A comprehensive review of catastrophic faults in PV arrays: types, detection, and mitigation techniques. IEEE Journal of Photovoltaics, 5(3), 982-997.

Andò, B., Baglio, S., Pistorio, A., Tina, G. M., \& Ventura, C. (2015). Sentinella: Smart monitoring of photovoltaic systems at panel level. IEEE Transactions on Instrumentation and Measurement, 64(8), 2188-2199.

BP Energy, BP Energy Outlook 2019 edition, 2019. https://www.bp.com/content/dam/bp/businesssites/en/global/corporate/pdfs/energy-economics/energy-outlook/bp-energy-outlook-2019.pdf (accessed December 8, 2020).

Chen, Z., Wu, L., Cheng, S., Lin, P., Wu, Y., \& Lin, W. (2017). Intelligent fault diagnosis of photovoltaic arrays based on optimized kernel extreme learning machine and IV characteristics. Applied

Chine, W., Mellit, A., Lughi, V., Malek, A., Sulligoi, G., \& Pavan, A. M. (2016). A novel fault diagnosis technique for photo voltaic systems based on artificial neural networks. Renewable Energy, 90, 501-512.

Chouder, A., \& Silvestre, S. (2010). Automatic supervision and fault detection of PV systems based on power losses analysis. Energy conversion and Management, 51(10), 1929-1937.

Drews, A., De Keizer, A. C., Beyer, H. G., Lorenz, E., Betcke, J., Van Sark, W. G. J. H. M., ... \& Bofinger, S. (2007). Monitoring and remote failure detection of grid-connected PV systems based on satellite observations. Solar energy, 81(4), 548-564.

Du, C. J., \& Sun, D. W. (2008). Object Classification. Computer vision technology for food quality evaluation, 81.

Duke Energy, NC PV DG program SEPA presentation. (2011) 1-14.

EPDK, Elektrik Piyasası Y1llı Sektör Raporu, (2018). https://www.epdk.org.tr/Detay/Icerik/3-0-24-3/elektrikyillik-sektor-raporu.

Gokmen, N., Karatepe, E., Silvestre, S., Celik, B., \& Ortega, P. (2013). An efficient fault diagnosis method for PV systems based on operating voltage-window. Energy conversion and management, 73, 350-360.

Guerriero, P., d'Alessandro, V., Petrazzuoli, L., Vallone, G., \& Daliento, S. (2013, June). Effective real-time performance monitoring and diagnostics of individual panels in PV plants. In 2013 International Conference on Clean Electrical Power (ICCEP) (pp. 14-19). IEEE.

Hernandez, J. C., \& Vidal, P. G. (2009). Guidelines for protection against electric shock in PV generators. IEEE Transactions on Energy Conversion, 24(1), 274-282.

Jung, T. H., Ko, J. W., Kang, G. H., \& Ahn, H. K. (2013). Output characteristics of PV module considering partially reverse biased conditions. Solar Energy, 92, 214-220.

Key world energy statistics, 2019. https://www.connaissancedesenergies.org/sites/default/files/pdfactualites/Key_World_Energy_Statistics_2019.pdf.

Köntges, M., Kurtz, S., Packard, C. E., Jahn, U., Berger, K. A., Kato, K., ... \& Miller, D. (2014). Review of failures of photovoltaic modules.

Mekki, H., Mellit, A., \& Salhi, H. (2016). Artificial neural network-based modelling and fault detection of partial shaded 
photovoltaic modules. Simulation Modelling Practice and Theory, 67, 1-13.

Mellit, A., Tina, G. M., \& Kalogirou, S. A. (2018). Fault detection and diagnosis methods for photovoltaic systems: A review. Renewable and Sustainable Energy Reviews, 91, 1-17.

Rezk, H., Tyukhov, I., Al-Dhaifallah, M., \& Tikhonov, A. (2017). Performance of data acquisition system for monitoring PV system parameters. Measurement, 104, 204-211.

SEPA, SEPA, (2018). http://www.yegm.gov.tr/MyCalculator/Default.aspx (accessed June 24, 2020).

Spagnuolo, G., Xiao, W., \& Cecati, C. (2015). Monitoring, diagnosis, prognosis, and techniques for increasing the lifetime/reliability of photovoltaic systems. IEEE Transactions on Industrial Electronics, 62(11), 7226-7227.

TEİAŞ, Electricity Statistics, 2019. https://www.teias.gov.tr/tr-TR/kurulu-guc-raporlari.

Triki-Lahiani, A., Abdelghani, A. B. B., \& Slama-Belkhodja, I. (2018). Fault detection and monitoring systems for photovoltaic installations: A review. Renewable and Sustainable Energy Reviews, 82, 2680-2692.

Zhao, Y., De Palma, J. F., Mosesian, J., Lyons, R., \& Lehman, B. (2012). Line-line fault analysis and protection challenges in solar photovoltaic arrays. IEEE transactions on Industrial Electronics, 60(9), 3784-3795.

Zhao, Y., Ball, R., Mosesian, J., de Palma, J. F., \& Lehman, B. (2014). Graph-based semi-supervised learning for fault detection and classification in solar photovoltaic arrays. IEEE Transactions on Power Electronics, 30(5), 2848-2858. 